\title{
Developing Additive Manufacturing Laboratory to Support Instruction and Research in Engineering Technology
}

\section{Dr. Mert Bal, Miami University}

Mert Bal received his $\mathrm{PhD}$ degree in Mechanical Engineering from the Eastern Mediterranean University, North Cyprus in 2008. He was a Post-Doctoral Fellow in the University of Western Ontario, and a Visiting Researcher at the National Research Council Canada in London, Ontario, Canada between 2008 and 2010. He was involved in various research projects in the areas of collaborative intelligence, localization and collaborative information processing in wireless sensor networks, intelligent agents, agent-based manufacturing scheduling, systems control and automation, distributed control of holonic systems and integrated manufacturing, agile manufacturing, additive manufacturing, virtual reality and remote laboratory applications in education.He has authored or co-authored various journal and conference publications in these areas. Mert Bal is currently an Associate Professor in the Miami University, Department of Engineering Technology, Ohio, United States of America.

\section{Dr. Ayodele O. Abatan, Miami University}

Dr. Ayo Abatan has over 30 years of program and project management experience. He is currently Professor and Chair of Engineering Technology in the College of Liberal Arts and Applied Science at Miami University of Ohio. Previously, Dr. Abatan was professor of engineering at Virginia Tech, Virginia Military Institute, Ahmadu Bello University, and Clark Atlanta University. During his academic tenure, Dr. Abatan has served as principal investigator of funding for research and education from major public and private sector organizations, including NSF, Boeing, NASA, and the US Army. He has also provided academic and administrative leadership for graduate and undergraduate programs. Dr. Abatan has published over 85 articles in major publications. His research interests include smart materials and structures; structural stability; structural health monitoring; impact dynamics of composites; and engineering education. 


\title{
Developing Additive Manufacturing Laboratory to Support Instruction and Research in Engineering Technology
}

\begin{abstract}
The need for Additive Manufacturing (AM) workforce poses new challenges to educational institutions offering engineering and engineering technology programs in integrating AM technology in their curricula in order to assure that their graduates are well prepared to the AM industry. The educational institutions need to design new courses or revise existing courses with hands-on laboratory components in order to introduce their students to AM technology and teach them how to design customized and complex products for current and future applications of AM using modern 3D printers. In order to address the growing workforce needs on AM technology, the Department of Engineering Technology at Miami University, Ohio has also launched an initiative for developing an Additive Manufacturing Laboratory (AM Lab), partially funded by a state equipment grant, for supporting educational and research activities in various engineering technology concentrations offered by the department. This paper presents the recently formed AM Lab initiative and discusses the use of the lab in supporting instruction and research activities in engineering technology. The paper also discusses the challenges and opportunities of integrating AM technology in engineering technology curriculum based on our experiences.
\end{abstract}

\section{Introduction}

Additive Manufacturing (AM) is an emerging technology that encompasses numerous three dimensional (3D) printing technologies for joining materials layer by layer to make objects from 3D computer-aided design (CAD) model data ${ }^{1,2}$. Through AM technology, complex geometric shapes, multi-material and multi-functional parts can be additively manufactured in a single operation which is a big advantage over conventional manufacturing processes. Over the past two decades, the intensive research carried out on AM technologies has yielded significant progress in the development and commercialization of new and innovative AM processes such as Fused Deposition Modeling (FDM), selective laser sintering, and other rapid prototyping methods, as well as numerous practical applications in aerospace, automotive, biomedical, civil, energy and other industries ${ }^{3,4}$. Large portion of the manufacturing industry has realized the benefits of the AM technology and started utilizing AM as an integral part of their processes. For example, General Electric (GE) Corporation has invested approximately $\$ 1.5$ billion in advanced manufacturing and additive technologies, in addition to building a global network of Additive centers focused on advancing the science ${ }^{5}$. The company uses the additive manufacturing processes for manufacturing its jet engine nozzles because it uses less material than conventional techniques. That reduces production costs and, because it makes the parts lighter, yields significant fuel savings for airlines. Conventional techniques would require welding about 20 
small pieces together, a labor-intensive process in which a high percentage of the material ends up being scrapped ${ }^{6}$.

The increasing use of AM technologies in the industry has created a stable demand for a skilled workforce of engineers and engineering technologists who are proficient in all aspects of the AM processes, from software-driven 3D designs to hands-on execution of these designs using modern $3 \mathrm{D}$ printing platforms ${ }^{7}$. In order to be competent, the training of modern engineers will need to include more advanced skills in CAD and optimization that focus on construction of 3D structures with a growing number of metal, plastic and gel materials through AM processes. An analysis by the Ohio Department of Job and Family Services, Bureau of Labor Market Information, June 2015, indicates significant growth in jobs and demand for skilled workers in Southwestern (SW) Ohio in the additive and advanced manufacturing and related occupations for aerospace and bio health industries. Computer and mathematics occupations are predicted to be the third largest growth area (6\% increase) in SW Ohio by the year 2022. Sixty percent of the fastest growing occupations in SW Ohio are in the bio health industries. In North American Industry Classification System (NAICS) occupational categories, the overall growth in jobs in SW Ohio in these fields is predicted to be nearly $21 \%$. Ohio in Demand Occupations projections indicate a growth of nearly 8,300 jobs in these fields, with annual openings of nearly 1,900 per year by the year $2022^{8}$.

The Department of Engineering Technology (ENT) at Miami University in Ohio offers ETACABET accredited engineering technology programs in three concentrations: Mechanical, Electromechanical and Electrical \& Computer Engineering Technology. The majority of students in the department are nontraditional students, primarily from the local industries. For this reason, the department offers a lot of evening classes. In order to address the growing workforce needs of SW Ohio region in advanced manufacturing, the department has recently launched a set of initiatives for additive manufacturing education that involves developing an additive manufacturing laboratory (AM Lab). The main goal of this initiative and the AM Lab is to support design education in various engineering technology concentrations by complementing CAD and manufacturing instruction with the AM equipment in order to better prepare students to handle the new industries demanding AM workforce.

In this paper, we mainly describe the newly formed AM Lab in the Department of ENT at Miami University, Ohio and present several application examples in order to demonstrate its function in supporting instruction in engineering technology. We also discuss the contributions of the AM lab to research and service centric activities at the department. 


\section{Additive Manufacturing Laboratory Overview}

The new AM Lab is partially funded by a state equipment grant which was recently awarded to the department by the Ohio Department Higher Education. The state grant was used to acquire several 3D scanning and printing equipment of various types in order to increase the number of engineering technologists who are trained in state-of-the-art AM methods.

The ENT Department is housed at the regional campuses of Miami University, Ohio which are mainly situated in Hamilton, Ohio and Middletown, Ohio. For the purpose of housing the new AM laboratory equipment, existing lab spaces in both of the campuses have been modified to create dedicated work areas. In choosing lab space for housing the AM Lab, we considered the following requirements, i) accessible location; the lab must be located in an accessible location for the students. ii) It must be in a close proximity to a lab technician or supervisor, who could operate the machines and assist or supervise students. At the initial stage of development, we chose our existing mechanical engineering technology lab in our Hamilton, Ohio campus. This lab houses the office of the department's technical services specialist, who is the main person-incharge of supervising the use of the lab equipment. The AM Lab consists of three CubePro ${ }^{\mathrm{TM}}$ polymer printers with capabilities to print various types of polymeric materials (PVS, ABS, Nylon etc.), two Makerbot ${ }^{\mathrm{TM}}$ Replicator PLA printers, one MCOR ${ }^{\mathrm{TM}}$ IRIS paper-based printer, a ProJet $^{\mathrm{TM}}$ 260c sandstone printer and a Nobel 1.0 ${ }^{\mathrm{TM}}$ UV Laser printer from XYZ Printing ${ }^{\mathrm{TM}}$. The lab also involves two Ultra HD 3D scanners from NextEngine ${ }^{\mathrm{TM}}$, and one Artec ${ }^{\mathrm{TM}}$ EVA-S scanner ${ }^{9,10 a . i .9}$. The layout of the AM Lab is shown in the Figure 1.

The CubePro ${ }^{\mathrm{TM}}$ a is a professional level, desktop 3D printer that uses FDM technique to print PLA and ABS nylon parts in up to three colors ${ }^{11}$. The machine is capable of rapid prototyping and engineering of small and medium size mechanical components. Similar to CubePro ${ }^{\mathrm{TM}}$, the MakerBot ${ }^{\mathrm{TM}}$ Replicator is a well-built and designed, affordable 3D printer ${ }^{12}$. Due to its price point, ease of use and compact size, it is one of the printer models which is suitable for educational activities. This printer also offers several connectivity options which could be suitable for online, distance-learning applications. 


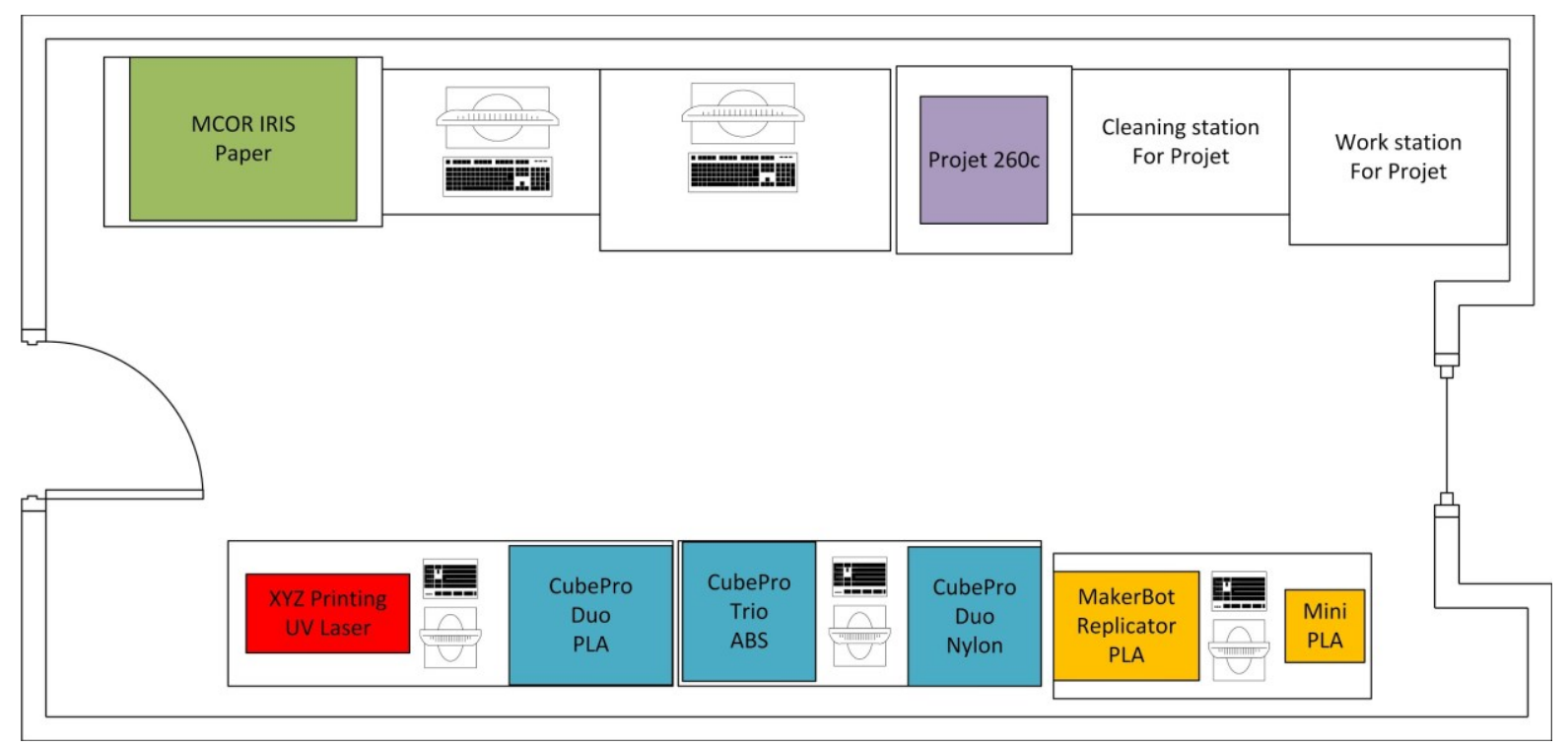

Figure 1: Layout diagram of the Additive Manufacturing Laboratory

The AM Lab also contains several new generation 3D printers with diverse printing techniques and materials. These printers have been particularly effective in demonstrating alternative 3D printing technologies and materials to engineering technology students as part of diverse activities in education. For example, the MCOR ${ }^{\mathrm{TM}}$ IRIS is a paper-based full color 3D Printer, which uses standard office letter paper to create functional 3D printing models. The system prints a slice of the 3D model on a piece of paper while laying down an adhesive. At the same time, a cutting blade traces the outline of the model, so once the print is complete the excess paper just needs to be gently removed ${ }^{13}$. This $3 \mathrm{D}$ printer also uses an existing $2 \mathrm{D}$ inkjet printer to print color on the standard paper in order to create true color 3D models. Figure 2 shows the $\mathrm{MCOR}^{\mathrm{TM}} 3 \mathrm{D}$ printer and some sample printed parts in the AM Lab.

Similarly, the ProJet ${ }^{\mathrm{TM}} 260 \mathrm{c}$ is another professional 3D printer, made by the 3D Systems, which uses material jetting technology to produce 3D models from sandstone materials ${ }^{14}$.The UV Laser printer uses Stereolithography (SLA) technique to print objects out of the resin materials. The principle of this printer is that it uses photopolymers as consumables. The material is initially liquid and it reacts to light by solidifying (See Figure 3). The machine activates the photo polymerization reaction by using a laser to solidify the object's layers ${ }^{15}$. 


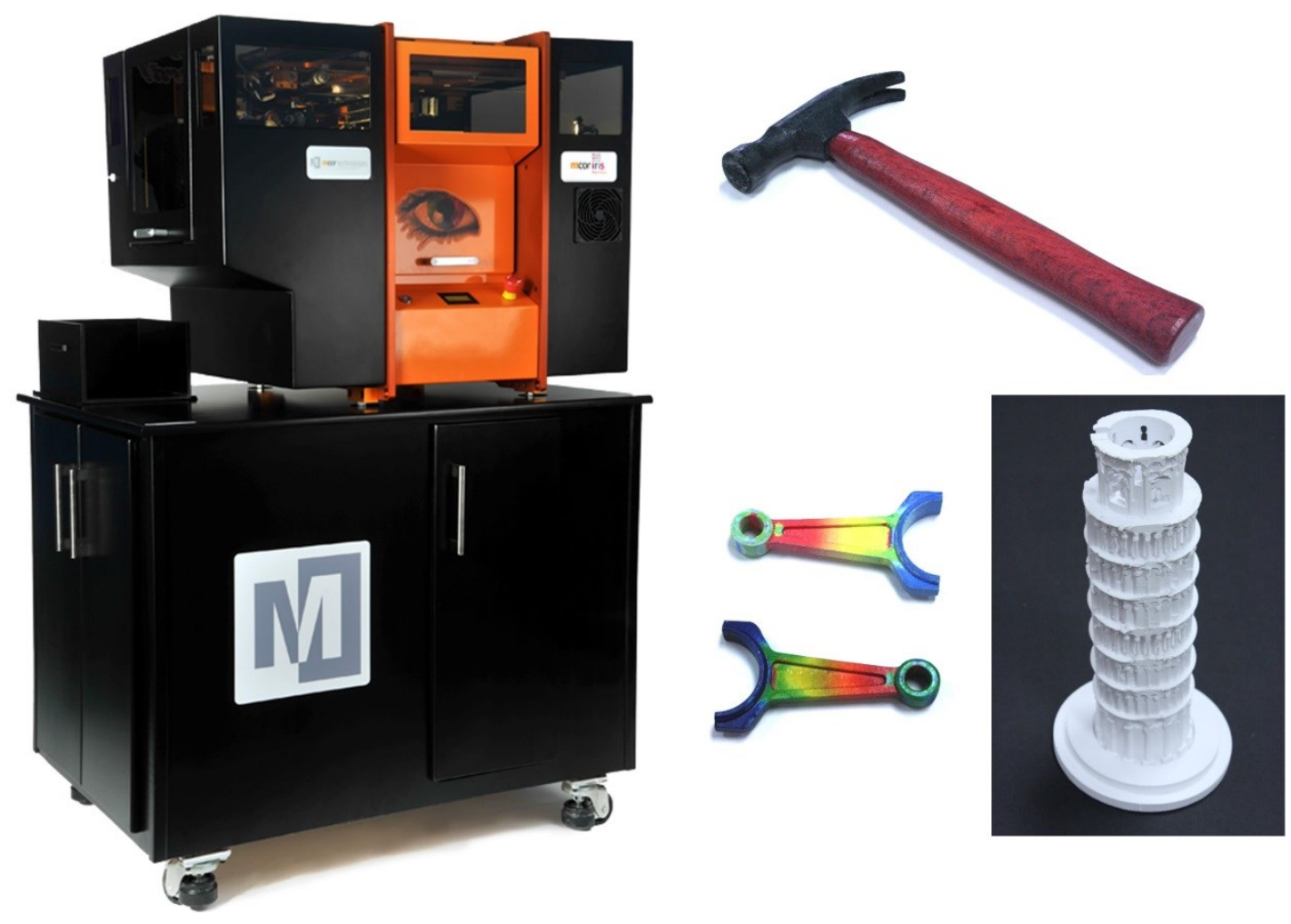

Figure 2: MCOR-IRIS Paper Printer (left) and sample printed parts (right)

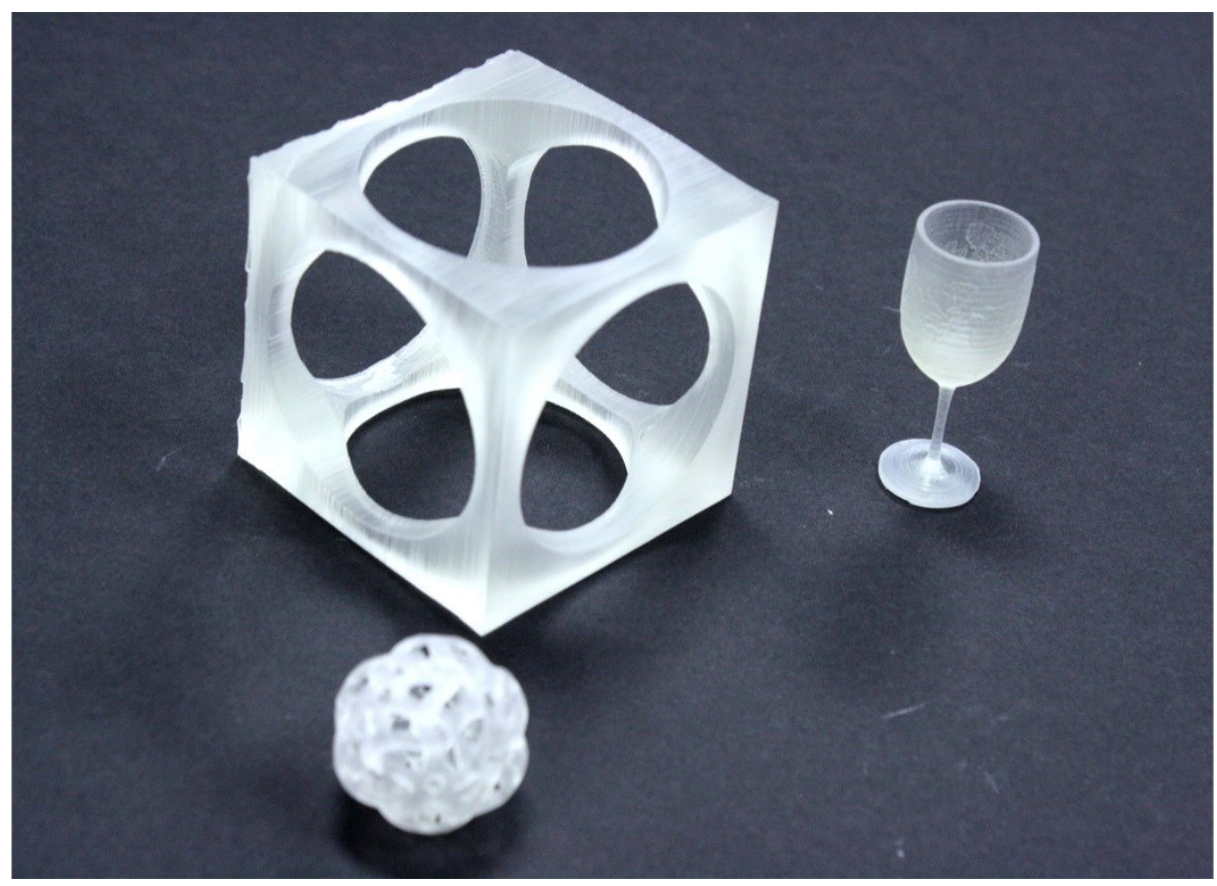

Figure 3: Sample parts printed on XYZ ${ }^{\mathrm{TM}}$ UV Laser Printer using photopolymer resin. 


\section{Applications in the Engineering Technology Curriculum}

In order to integrate the AM concepts in the engineering technology curriculum and provide adequate hands-on training to the students with the new lab equipment, there has been significant modifications done in some the core courses in the Department of ENT. These include, adding new AM-related course modules, creating new design projects that require 3D printing applications, and developing new AM laboratory exercises in existing courses. The new AM Lab has also enabled expanding some of the community outreach and research activities in the department. This section discusses some of the application examples that has taken place in the Department of ENT using the new AM Lab.

\section{a. Race-Car Design Project in a Computer-Aided Manufacturing Course}

The Race-Car is a team-based, semester-long, course project in a sophomore-level ComputerAided Manufacturing (CAM) course. Each team consists of 3-4 students and it is to design and manufacture a working prototype mini-car with machined and 3D-printed parts. The students are required to use $\mathrm{CAD}$ software (e.g., AutoCAD ${ }^{\mathrm{TM}}$ ) to design their projects. For manufacturing, the student are expected to use a combination of $\mathrm{CNC}$ machining and 3D printing. Student use CAM software to generate the G-code to machine some of the project parts. Car bodies, gears and other parts must be designed for and printed on a 3D printer. For 3D printing, the students are provided an access to the equipment in the AM lab. They use software to prepare STL files and 3D print their car using an FDM-based printer with PLA or ABS as the material. Despite the presence of multiple printers in the lab, scheduling time on the machines is critical in order for each team to gain equal access to the $3 \mathrm{D}$ printers. Hence, students must schedule their own time slots with the laboratory supervisor to work on the printers. Once the projects are completed, all the projects are evaluated by judging and a mini-competition at the end of the semester. See Figure 4 for completed race cars with 3D-printed parts.

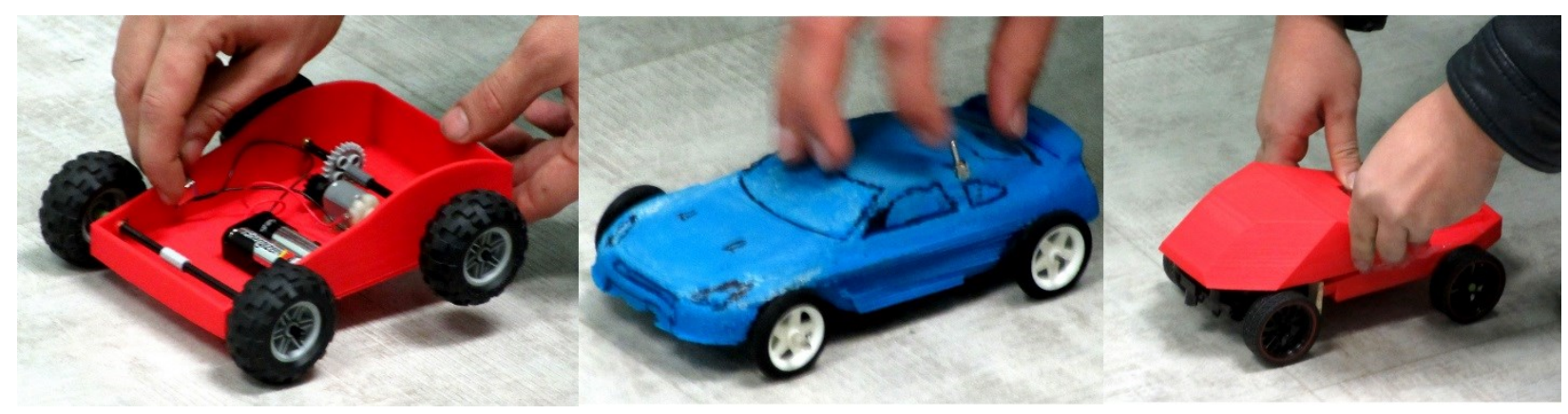

Figure 4: 3D Printed mini race cars completed by the students for competition 


\section{b. Distance-Learning Course on Manufacturing Systems}

Department of ENT at Miami University, Ohio offers a distance-learning program in its Electromechanical and Electrical \& Computer Engineering Technology concentrations. In partnership with 12 regional community and technical colleges, we broadcast our distancelearning courses in real-time to a large group of remote students, who reside across the state via interactive video (IVDL) and web-based video conferencing.

The ENT 407 - Modern Manufacturing Systems is a senior-level course, which is mainly taken by distance-learning students. The course is delivered in hybrid and blended format through IVDL and Web. The course contents cover a broad range of topics including the review of manufacturing processes and systems and techniques for Design for Manufacturing (DFM) and Design for Assembly (DFA). With acquisition of the new AM Lab equipment, there has been a few modifications in this course in order to include AM topics in this course with some hands-on activities. Students are first given an introductory lecture on the history of additive manufacturing and 3D printing, the current applications, materials being used, methods of 3D printing, and the projections for the next few years. The students are then given hands-on experience on using 3D modeling and designing software to create and print their design. In this course, we relate the hands-on experience on 3D printing to another course module about the DFM and DFA concepts. As one of the course assignments, the students are asked to design a product that is easily and economically manufactured. They are expected to utilize the design techniques for DFM and DFA and integration of product design and process planning into one common activity. Students are asked to consider realistic constraints of the AM technology is this process, and design their parts for AM process. Once they complete their design, they generate 3D models and print their design in the AM Lab. For 3D CAD modeling, students use a free, cloud-based CAD tool i.e. AutoDesk ${ }^{\mathrm{TM}}$ TinkerCAD. They also download and use the recent versions of the MakerBot ${ }^{\mathrm{TM}}$ and/or CubePro ${ }^{\mathrm{TM}}$ 3D Printing Software for preparing their designs for $3 \mathrm{D}$ printing. These software are also freely available online at no cost. Due to the restrictions of the distance delivery format, the hands-on portion of this project has to be carried out remotely with the help of the AM Lab staff. Students contact the AM Lab supervisor to schedule times in order to perform their 3D printing in one of the FDM machines using PLA, ABS or Nylon type materials. Optionally, students can use the cloud-connectivity features of some 3D printing machines in order to monitor the $3 \mathrm{D}$ printing process remotely via a web-camera. We are currently working on improving this process in order to deliver more effective hands-on experience to distance-learning students. 


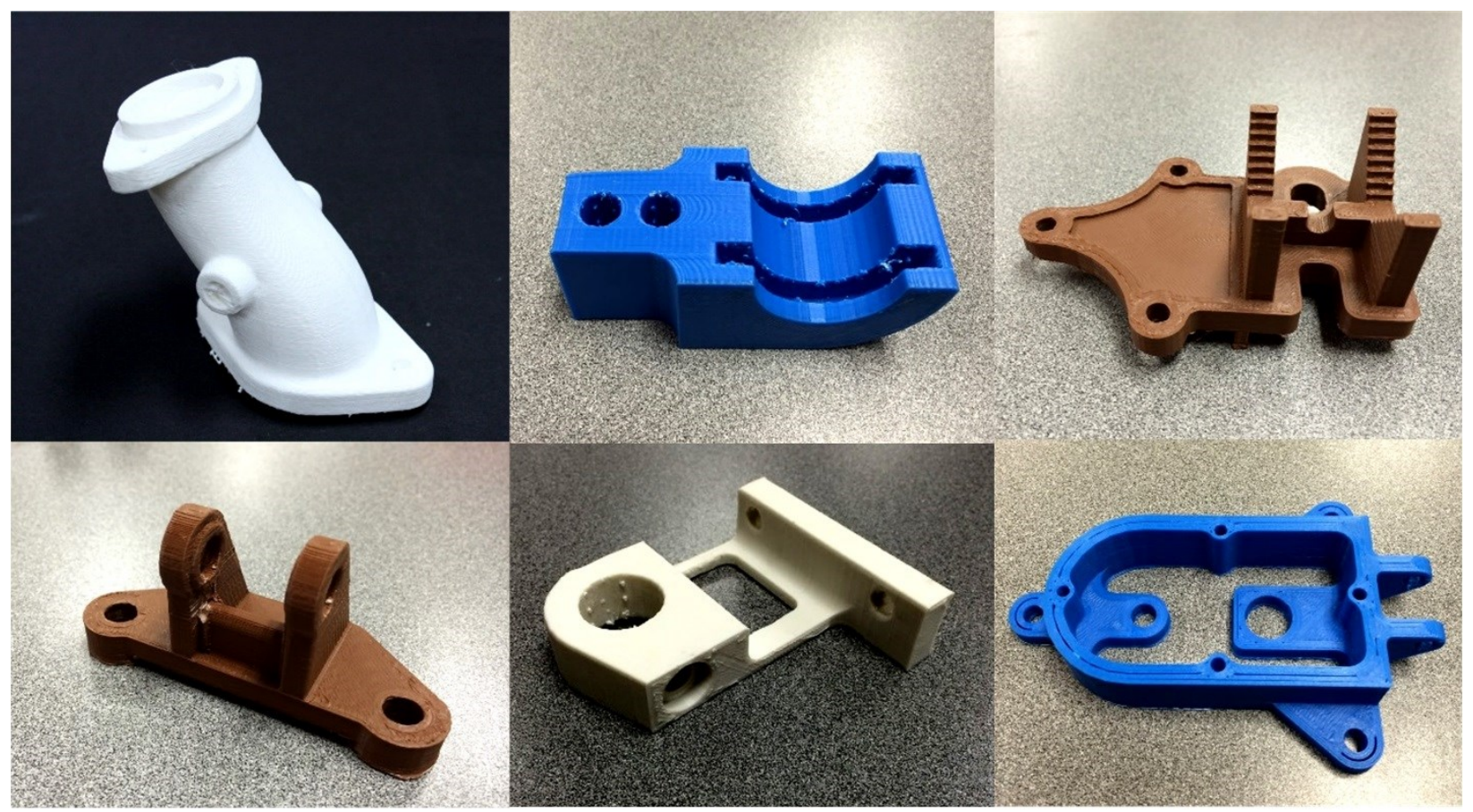

Figure 5: Student design projects in a distance-learning course on manufacturing

\section{c. Term Projects in a Freshman-Level CAD Course}

The ENT135 - Computer Aided Drafting is a freshman-level course in the Department of ENT, which covers techniques for basic 2D drafting, orthographic projection, geometric dimensioning and tolerance and basic 3D modeling techniques to create solid models with appropriate design intent. The course content is delivered in project based lab activities using AutoCAD ${ }^{\mathrm{TM}}$ as the modeling platform.

In order to improve design skills with complex geometries, and have them exposed to AM technologies, the term project assignment of this class has been modified by adding more requirements to the term projects so that the students will design by looking from the aspect of additive manufacturing technology. Each student is assigned a term project to design and prototype a product using the equipment in the AM Lab. After having given basic dimensional and functional requirements of the product they are designing, the students are asked to design their product with complex features and use the advantages of the AM for generating a physical prototype of it. Students are left free to work on their project during the class periods and their efforts are systematically observed during the class presentations. Figures $6 \mathrm{a}$ and $6 \mathrm{~b}$ show sample parts designed and printed by the students. These parts are printed with MakerBot ${ }^{\mathrm{TM}}$ and CubePro $^{\mathrm{TM}}$ FDM printers using PLA and Nylon materials. 

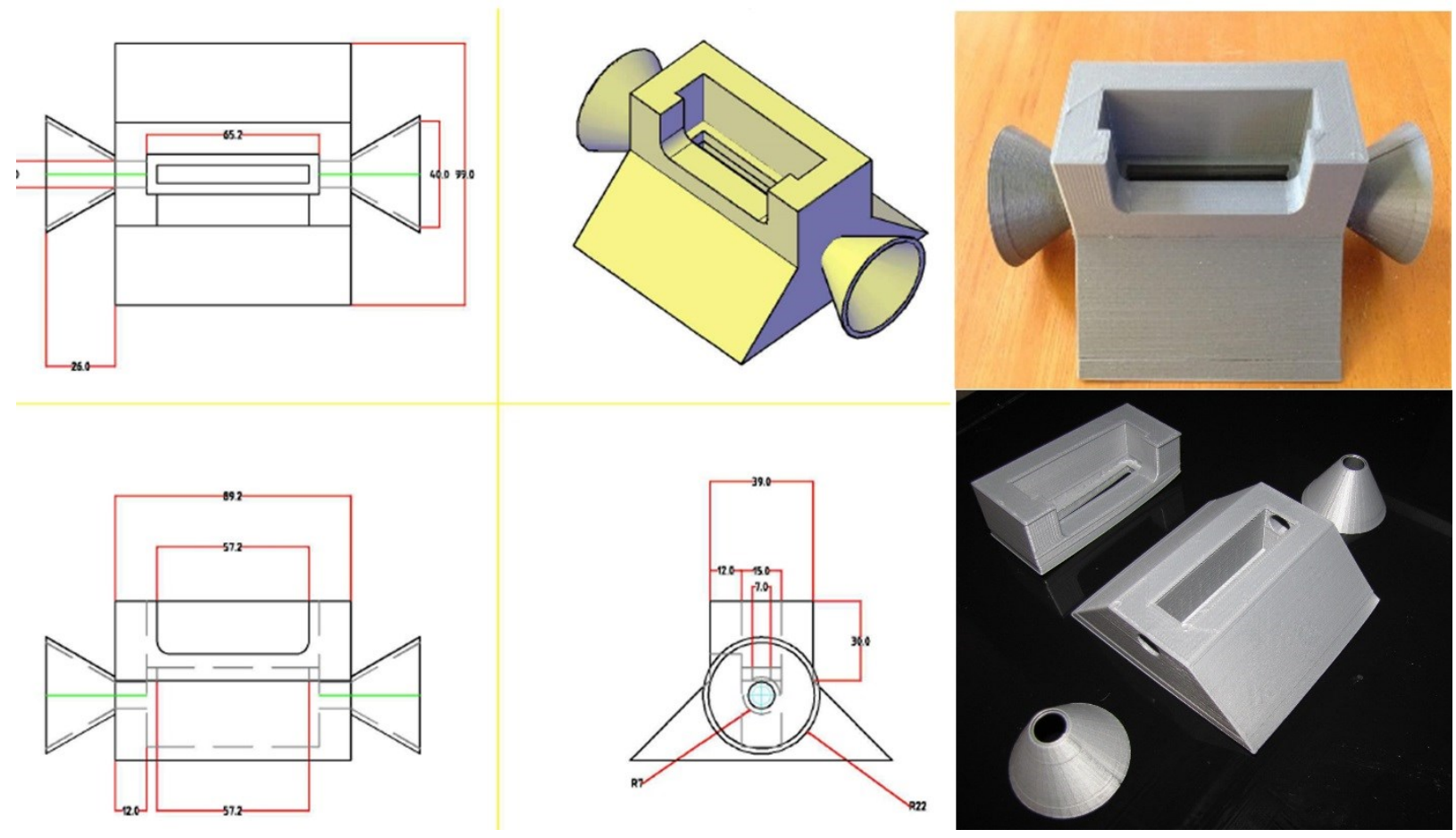

Figure 6a: A 3D printed class project in the freshman-level CAD course

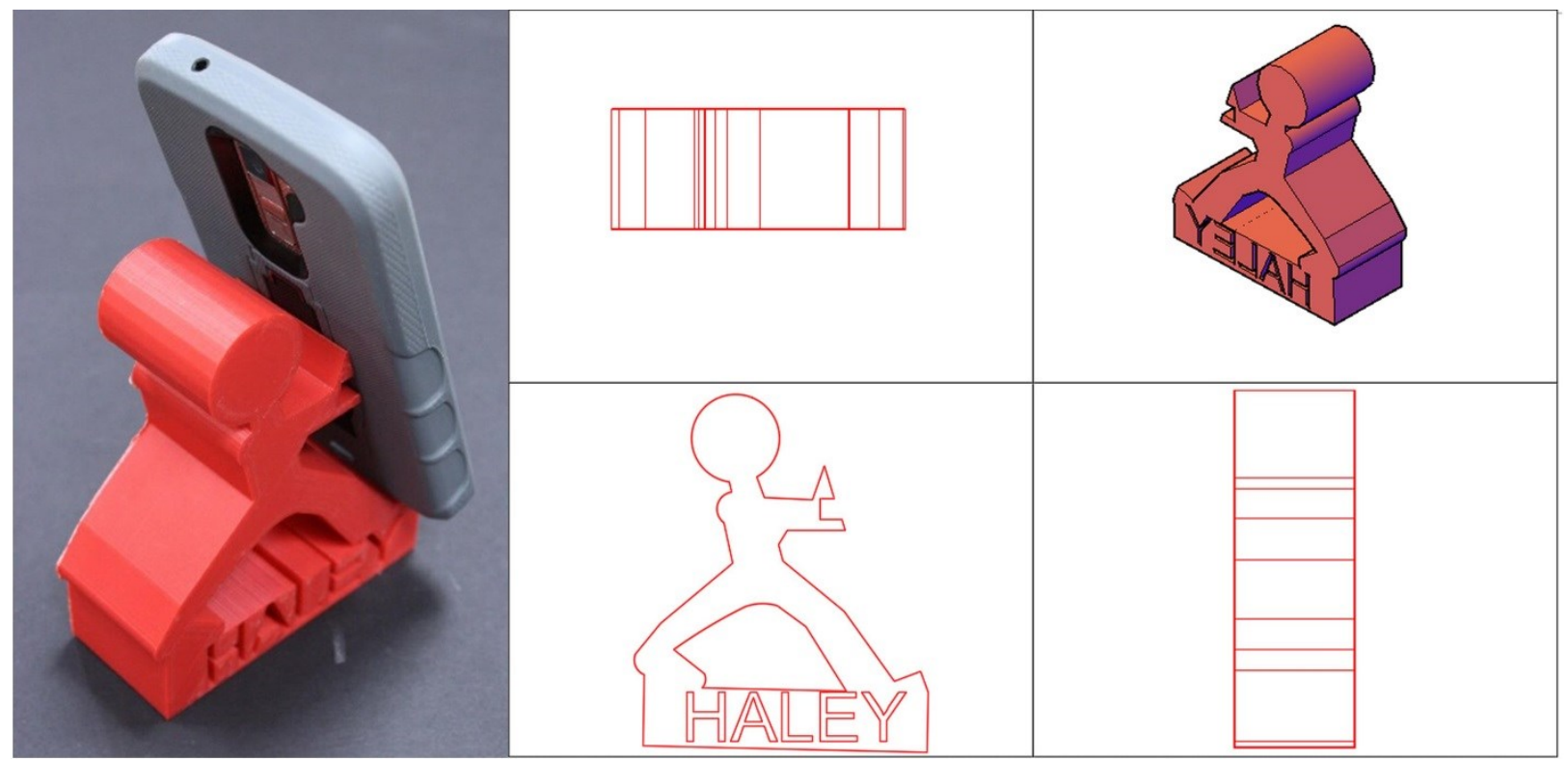

Figure 6b: A 3D printed smartphone stand designed by a freshman 


\section{Applications in Research, Community Engagement and Outreach}

\section{a. Utilizing AM in Student Research through Senior Design Capstone Course}

Engineering technology curriculum of the Department of ENT at Miami University, Ohio includes a capstone course, which consists of a sequence of two semester-long courses namely: ENT 497-Senior Design Project I and ENT 498-Senior Design Project II. The students conduct major open-ended research and design projects utilizing their knowledge and skills acquired in earlier course work, work in teams, and incorporate engineering standards. The projects offered in this course are chosen from real-world problems. Design projects include the establishment of objectives and design criteria, procedural synthesis, engineering analysis, and evaluation. In all designs, students will consider realistic constraints, such as economic factors, marketability, human factors, safety, reliability, aesthetics, ethics, and social impacts. The first part of the project (ENT 497) deals with feasibility studies or proposals. The second part (ENT 498) is the actual implementation, testing, and production or simulation of the prototype ${ }^{16}$.

The AM Lab initiative has added a new dimension to the senior design sequence as it provided opportunities to the senior students to quickly prototype and test such design projects. The students in the senior design project course are encouraged to utilize the AM Lab equipment in rapid prototyping phases of their projects. They are also encouraged to consider AM technology as the focus area in their project. Over the course of the past three years, a lot of student teams utilized AM equipment in the lab to print parts in order to be used for building prototypes of their designs. For example, a student team designed and printed a series of gears using the FDM printer to be used as a demonstration device for the mechanical machine design courses. The device is powered by a DC motor and is capable of several speeds.

Some teams chose the AM technology as their focus and they carried out design improvements on the AM processes and equipment as part of their senior design projects. Recently, a student team evaluated the capabilities of FDM 3D printed parts for strength, geometry and dimensional accuracy for potential use in consumer products. The evaluation was done using a CubePro ${ }^{\mathrm{TM}}$ FDM printer. Results included geometric and dimensional tolerances, mechanical properties, anisotropic properties, flatness, concentricity, and parallelism. See Figure 7 for the parts printed with CubePro ${ }^{\mathrm{TM}}$ for this evaluation. 

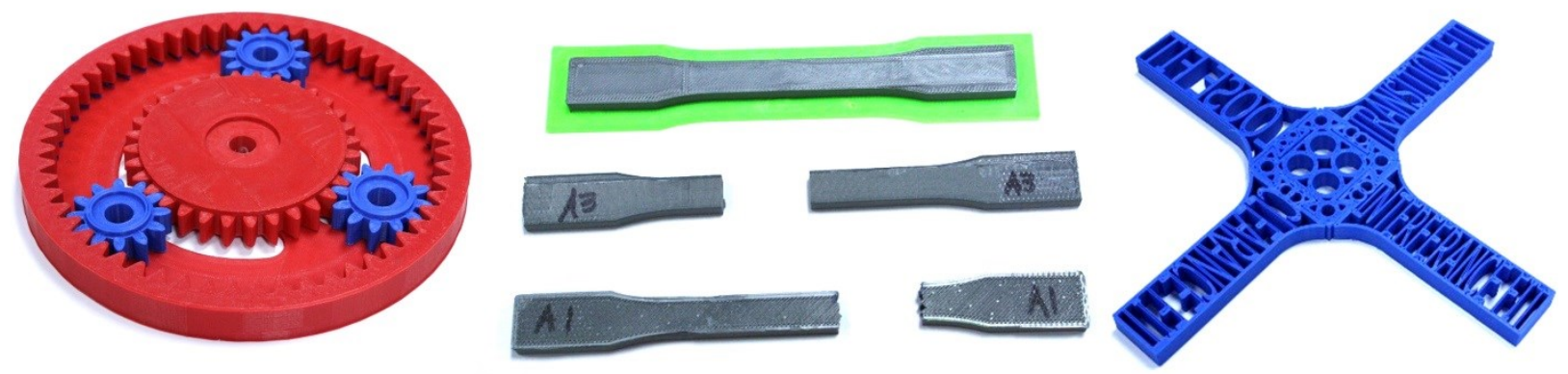

Figure 7: Sample parts printed with CubePro ${ }^{\mathrm{TM}}$ for student design projects

In many ways, the senior design project course is considered as one of the best opportunities to involve undergraduate engineering technology students in research. Several faculty members, who work on various research projects, often work with students as advisors or mentors and allow the students to contribute to their research projects by designing and testing of their prototypes.

\section{b. Offering STEM Workshops for Area High Schools}

In partnership with regional high-schools and community colleges, our department regularly offers high school mechanical and electronics engineering-focused STEM workshops by inviting groups of students from area high schools to visit our campuses with the aim of increasing and stimulating their knowledge and motivation towards engineering. In these activities, we offer basic engineering activities in the fields of mechanical and electrical and electronics engineering technology. Since the addition of the new AM Lab to the department, we have also started focusing on developing and offering AM-themed activities in these workshops.

The AM activities involve designing a simple product using virtual modelling environments (AutoDesk ${ }^{\mathrm{TM}}$ or SolidEdge ${ }^{\mathrm{TM}}$ ), prepare and 3D print the developed design by considering its various related layer properties. To meet this objective, the students are divided into two groups. They are first given a short lecture about 3D printing methods and materials used. Then, in interactive hands on sessions, the students are taught how to use the modeling software to create their designs, create STL files, and prepare their models for 3D printing using slicing software (See Fig 8). At the end of the workshop, the students print their designs in the AM Lab. The AM focused workshops have been highly effective in increasing students' interest in the field of STEM. As per the feedback we obtained through surveys, the students believe that the workshops have provided them with technical knowledge on 3D printing, and useful hands-on experience through the completion of their project. Over the course of the 2015-16 and 2016-17 academic years, we carried out total of two workshops, one with attendance of 20 students and the other one with 21 students from area high schools. At each workshop, each student made one 
Solid Edge drawing using the instructions provided in the workshop, and generated one 3D printing using one of the CubePro printers out of PLA filaments using FDM as the AM technique.

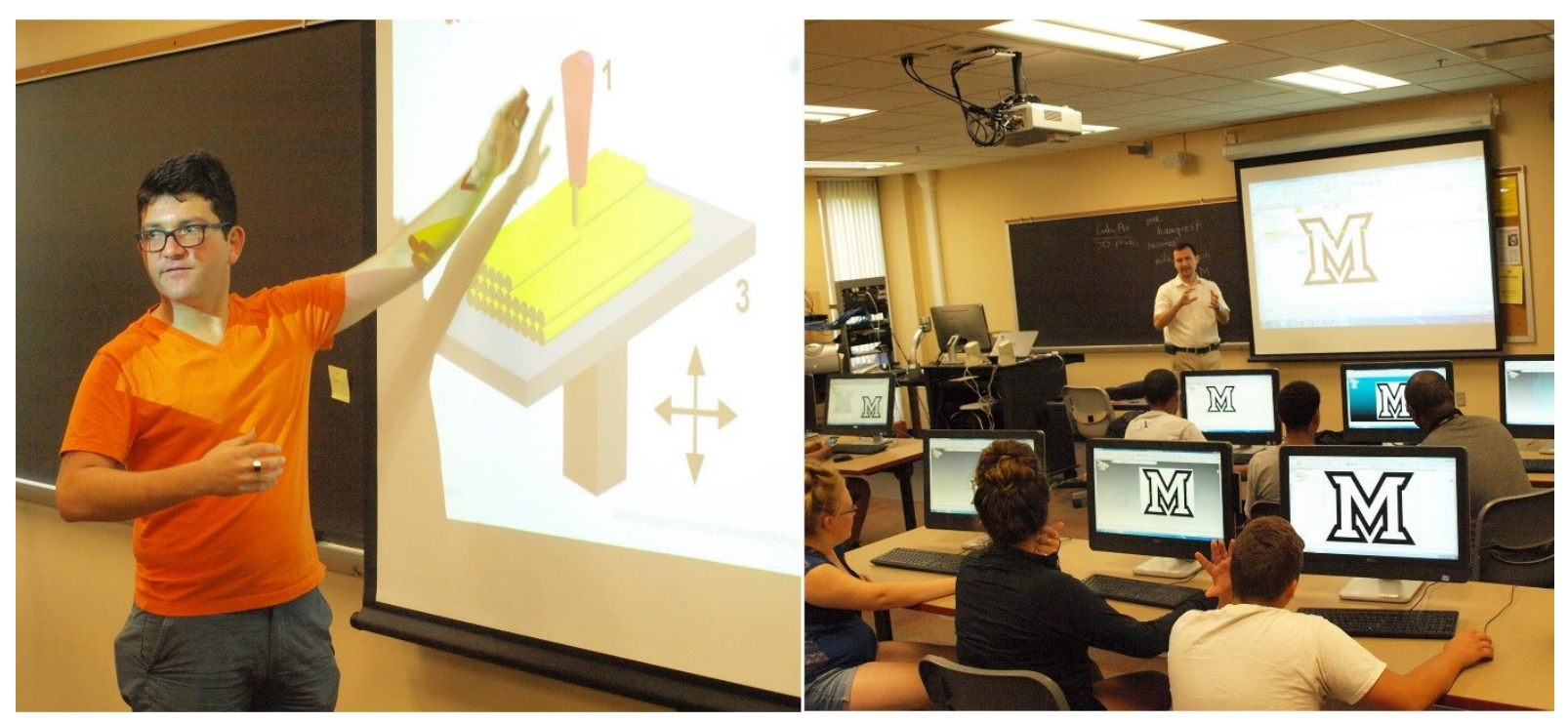

Figure 8: Photos taken during the AM-focused High-School Workshop Activity

\section{Conclusions}

In many ways, the AM Lab initiative presented in this paper has been a significant addition in supporting instructional and research activities of the Department of ENT at Miami University, Ohio. The Department of ENT, with baccalaureate majors in Mechanical, Electromechanical and Electrical \& Computer Engineering Technology utilizes the new AM Lab equipment to complement instruction in existing courses and enhance student projects in all of its educational programs. The students are introduced to design and development process using AM technology. They can quickly prototype proof-of-concept models for their designs, and they can build physical models to test their design projects. In addition to supporting engineering technology courses, the AM Lab is also instrumental in several other ways such as: building prototypes for research projects, offering 3D printing STEM workshops, carrying out recruitment and demo sessions for prospective students and offering various 3D printing services for students and faculty of the greater campus community. Recently, the Department of ENT has developed a new introductory course on AM as an elective service course intended for engineering or nonengineering majors, who want to learn about $\mathrm{AM}$ and gain skills in modeling and operating $3 \mathrm{D}$ printing hardware. We anticipate to offer this introductory course in the upcoming winter term. We will measure the learning outcomes of this new elective and publish the assessment results along with our experiences in a future ASEE conference. The added value of the AM Lab at 
Miami University is the reality that it allows students to be exposed to the understanding of the behavior and performance of different materials used in AM processes.

Through the AM equipment investments and educational program enhancements presented in this paper, we are poised to significantly impact the available workforce for the In-Demand occupations of manufacturing engineers and technicians.

\section{Acknowledgement:}

The development of the AM Lab at the Regional Campuses of Miami University was partially funded by grants from both the Ohio Department of Higher Education (ODHE) and the Armin J. Fleck Trust.

\section{References:}

1. Serdar, T. (2016, June), Educational Challenges in Design for Additive Manufacturing Paper presented at 2016 ASEE Annual Conference \& Exposition, New Orleans, Louisiana. 10.18260/p.27294

2. ASTM, (2009), ASTM International Committee F42 on Additive Manufacturing Technologies, ASTM F279210 Standard Terminology for Additive Manufacturing Technologies, ASTM, West Conshohocken, PA.

3. Pahl, G., \& Beitz, W. (2013), Engineering design: a systematic approach. Springer Science \& Business Media.

4. Nannan GuoMing C. Leu. (2013), Additive manufacturing: technology, applications and research needs, M.C. Front. Mech. Eng. 8: 215. doi:10.1007/s11465-013-0248-8

5. Press release (2017). GE to develop competitive financing to stimulate growth in additive manufacturing, Available Online: http://www.geadditive.com/press-releases/ge-develops-competitive-financing-to-stimulategrowth-in-additive-manufacturing)

6. LaMonica, M. (2017) Additive Manufacturing GE, the world's largest manufacturer, is on the verge of using 3-D printing to make jet parts. MIT Technology Review, Available Online: https://www.technologyreview.com/s/513716/additive-manufacturing/

7. Agarwala, R., \& Chin, R. A. (2015, June), Facilitating Additive Manufacturing Engagement and Outreach Paper presented at 2015 ASEE Annual Conference and Exposition, Seattle, Washington. 10.18260/p.24086

8. Ohio Department of Job and Family Services, Bureau of Labor Market Information, http://ohiolmi.com/

9. 3D Laser Scanner, NextEngine, Available Online: https://www.nextengine.com/

10. Artec Eva: Fast 3D scanner for professionals. Artec3D, Available Online: https://www.artec3d.com/3dscanner/artec-eva

11. CubePro 3D Printer, 3D Systems, Available Online: https://www.3dsystems.com/shop/cubepro

12. Makerbot, Available Online: https://www.makerbot.com/

13. Grunewald, S.J. (2015), Mcor is Bringing Full High Definition Color to 3D Printing with Mcor IRIS HD, 3dprint.com, Available Online: https://3dprint.com/66759/mcor-iris-hd/

14.ProJet ${ }^{\mathbb{B}}$ CJP 260C, 3DSystems, Available Online: https://www.3dsystems.com/3d-printers/personal/projet$\underline{260 \mathrm{c}}$

15.Resin 3D Printer, XYZ Printing, Available Online: http://us.xyzprinting.com/us en/Product/resin

16. Hergert, D., \& Earley, R., \& Bommaraju, S. (2003, June), Incorporating Liberal Education Concepts Into Engineering Technology Senior Design Course At Miami University Paper presented at 2003 Annual Conference, Nashville, Tennessee. https://peer.asee.org/12402 